\title{
Article \\ Comparative Evaluation of the Phytochemical Profiles and Antioxidant Potentials of Olive Leaves from 32 Cultivars Grown in China
}

\author{
Chengcheng Zhang ${ }^{1}$, Xiaoting Xin ${ }^{1}$, Jianming Zhang ${ }^{1}$, Shenlong Zhu ${ }^{2}$, Erli Niu ${ }^{2}$, Zhongjing Zhou ${ }^{3}$ \\ and Daqun Liu ${ }^{1, *(1)}$
}

Citation: Zhang, C.; Xin, X.; Zhang, J.; Zhu, S.; Niu, E.; Zhou, Z.; Liu, D.

Comparative Evaluation of the

Phytochemical Profiles and Antioxidant Potentials of Olive Leaves from 32 Cultivars Grown in China. Molecules 2022, 27, 1292. https://doi.org/10.3390/ molecules27041292

Academic Editors: Eulogio

J. Llorent-Martínez and

Gokhan Zengin

Received: 11 January 2022

Accepted: 11 February 2022

Published: 15 February 2022

Publisher's Note: MDPI stays neutral with regard to jurisdictional claims in published maps and institutional affiliations.

Copyright: (C) 2022 by the authors. Licensee MDPI, Basel, Switzerland. This article is an open access article distributed under the terms and conditions of the Creative Commons Attribution (CC BY) license (https:// creativecommons.org/licenses/by/ $4.0 /)$.
1 Food Science Institute, Zhejiang Academy of Agricultural Sciences, Hangzhou 310021, China; zccwsf@126.com (C.Z.); xxt4228@sina.cn (X.X.); zhangjianming@zaas.ac.cn (J.Z.)

2 Institute of Crop and Nuclear Technology Utilization, Zhejiang Academy of Agricultural Sciences, Hangzhou 310021, China; zhus1@zaas.ac.cn (S.Z.); niuerli@zaas.ac.cn (E.N.)

3 State Key Laboratory for Managing Biotic and Chemical Threats to the Quality and Safety of Agro-Products, Zhejiang Academy of Agricultural Sciences, Hangzhou 310021, China; zhouzj@zaas.ac.cn

* Correspondence: liudaqun@zaas.ac.cn

\begin{abstract}
Olives (Olea europaea L.) are a significant part of the agroindustry in China. Olive leaves, the most abundant by-products of the olive and olive oil industry, contain bioactive compounds that are beneficial to human health. The purpose of this study was to evaluate the phytochemical profiles and antioxidant capacities of olive leaves from 32 cultivars grown in China. A total of 32 phytochemical compounds were identified using high-performance liquid chromatography-electrospray ionizationtandem mass spectrometry, including 17 flavonoids, five iridoids, two hydroxycinnamic acids, six triterpenic acids, one simple phenol, and one coumarin. Specifically, olive leaves were found to be excellent sources of flavonoids (4.92-18.29 mg/g dw), iridoids (5.75-33.73 mg/g dw), and triterpenic acids (15.72-35.75 mg/g dw), and considerable variations in phytochemical content were detected among the different cultivars. All tested cultivars were classified into three categories according to their oil contents for further comparative phytochemicals assessment. Principal component analysis indicated that the investigated olive cultivars could be distinguished based upon their phytochemical profiles and antioxidant capacities. The olive leaves obtained from the low-oil-content $(<16 \%)$ cultivars exhibited higher levels of glycosylated flavonoids and iridoids, while those obtained from high-oil-content ( $>20 \%$ ) cultivars contained mainly triterpenic acids in their compositions. Correspondingly, the low-oil-content cultivars (OL3, Frantoio selection and OL14, Huaou 5) exhibited the highest ABTS antioxidant activities (758.01 \pm 16.54 and $710.64 \pm 14.58 \mathrm{mg}$ TE/g dw, respectively), and OL9 (Olea europaea subsp. Cuspidata isolate Yunnan) and OL3 exhibited the highest ferric reducing/antioxidant power assay values $(1228.29 \pm 23.95 \mathrm{mg}$ TE/g dw and $1099.99 \pm 14.30 \mathrm{mg} \mathrm{TE} / \mathrm{g} \mathrm{dw}$, respectively). The results from this study may be beneficial to the comprehensive evaluation and utilization of bioactive compounds in olive leaves.
\end{abstract}

Keywords: olive leaves; cultivars; phenolic compounds; flavonoids; secoiridoids; antioxidants

\section{Introduction}

The olive tree (Olea europaea L.) is a famous woody oil species native to the Mediterranean and is one of the most important industrial crops in the world [1]. To meet the high demand for olive oil and table olives, which represent olive products with health benefits, olive trees have been cultivated around the world, including in South America, India, Australia, and China [2]. Given their wide distribution, olive trees generate large quantities of by-products, which can cause substantial environmental issues. Olive leaves are the most abundant by-products and are generated from the pruning of olive trees, harvesting of olive fruits, and olive oil processing. Previously, the leaves were typically used 
as animal feed or incinerated. These applications have no commercial value and can cause resource waste and environmental damage [3]. Olive leaves possess numerous properties beneficial to human health, due to their high content of bioactive compounds. Reports have shown that olive leaves are rich in a wide variety of bioactive compounds, including flavonoids (luteolin-7-O-glucoside, rutin, apigenin, and luteolin), phenolic acids (caffeic acid, ferulic acid), secoiridoids (oleuropein, verbascoside), and pentacyclic triterpenes [1,4]. All of these compounds have remarkable biological properties, including antimicrobial, antiviral, anti-inflammatory, hypoglycemic, and antioxidant activities [5,6]. As a result, the utilization of olive leaves to obtain value-added products rich in bioactive compounds could create new economic options for the olive trade and reduce the environmental burden generated by these residual products. In recent decades, the comprehensive use of olive leaves has been the focus of increasing interest $[7,8]$. For example, olive leaf flour has been used as an ingredient for the development of healthy crackers [9], and olive leaf extracts have been marked as natural antioxidants to improve the stability of edible oils [10] and to extend the shelf-life of gluten-free bread [11]. In summary, olive leaves have a myriad of potential applications in value-added commercial products, such as in food ingredients, nutraceuticals, pharmaceuticals, and cosmetics.

Phenolic compounds represent one of the major classes of active compounds in plants; they are the main contributors to plant bioactivity [1,12]. The bioactivity of olive leaf extracts appears to be partly related to the antioxidant activity and various phenolic compounds in the leaves $[13,14]$. The composition, concentration, and antioxidant behavior of the phenolic compounds may affect the applications of olive leaves. Several factors can affect the phenolic profiles of olive leaves, such as cultivar/genotype, developmental stage, climate, season, and subsequent processing, such as the drying conditions, temperature, light, and oxygen exposure [15-19]. Among these, the cultivar/genotype will significantly affect the type and concentration of the phenolic compounds. In a previous study, the phenolic spectra of 15 olive leaf varieties were characterized by high-performance liquid chromatography (HPLC) coupled with electrospray ionization and quadrupole time-offlight mass spectrometry, and the results showed that the types and concentrations of phenolic substances varied greatly among the varieties [15]. In another study, the qualitative and quantitative analyses of phenolic compounds in nine olive leaf genotypes showed significant differences in phenolic compound concentrations [20]. In 1956, olive trees were introduced into China from the Mediterranean [2], and, after 55 years of trial and cultivation, they have become a significant part of the agroindustry in China, with a total olive cultivation area of $80,000 \mathrm{hm}^{2}$ [21]. Although several studies have investigated the phenolic concentration and antioxidant activities of olive leaves, the phytochemical compounds and antioxidant activities of China-grown olive leaves have not been systematically studied, and information on the contributions of individual phytochemicals of olive leaves on their antioxidant activity is limited.

To our knowledge, oil content is the most important economic factor for the characterization of olive cultivars $[22,23]$. Accordingly, it is indubitably important to take into account not only phytochemical profiles in leaves but also oil content in the fruits for the comprehensive utilization of olive leaves among different cultivars. In the present study, the phytochemical compositions and antioxidant activities of olive leaves from 32 cultivars grown in China, including nine high-oil-content $(>20 \%), 12$ medium-oil-content $(16-20 \%)$ and 11 low-oil-content $(<16 \%)$ cultivars, were systematically investigated. Moreover, olive cultivar evaluation from both oil contents and phytochemical profiles in leaves was conducted simultaneously for the first time. Furthermore, the relationships between the individual phytochemicals and antioxidant capacities of the leaves were analyzed to define which bioactive compounds were responsible for antioxidant activity. The results of this work may be useful for valorizing olive leaves as value-added functional ingredients for functional foods, cosmetics, and medicine. 


\section{Materials and Methods}

\subsection{Chemicals and Reagents}

All chemicals and reagents used in this study were of analytical grade unless stated otherwise. Trolox, gallic acid, Folin-Ciocalteu phenol reagent, 2,2-diphenyl-1-picrylhydrazyl (DPPH), 2,2-azino-bis (3-ethylbenzothiazoline-6-sulfonic acid) diammonium salt (ABTS), and 2,4,6-tris (2-pyridyl)-s-triazine (TPTZ) were purchased from Sigma-Aldrich (St. Louis, MO, USA). Standard compounds such as hydroxytyrosol, esculin, taxifolin, luteolin, quercetin, kaempferol, apigenin, chlorogenic acid, plantamajoside, rutin, eriodictyol, tiliroside, apigenin-7-O-neohesperidoside, apigenin-7-O-glucoside, luteolin-7-O-glucoside, oleuropein, secoxyloganin, asiatic acid, oleanonic acid, maslinic acid, corosolic acid, oleanolic acid, and ursolic acid were purchased from Yuanye Bio-Technology Co., Ltd. (Shanghai, China). For chromatography analysis, HPLC-grade acetonitrile and acetic acid were purchased from Merck (Darmstadt, Germany) and Alfa Aesar (Shanghai, China), respectively. Ultrapure water supplied by a Milli-Q system (Millipore, Bedford, MA, USA) was used throughout the experiments.

\subsection{Plant Material Preparation}

Thirty-two olive cultivars were selected for investigation. All cultivars were planted in the research garden of the Institute of Crops and Nuclear Technology Utilization at the Zhejiang Academy of Agricultural Sciences, China under the same agronomic and environmental conditions. Details and pictures of the olive leaves are summarized in Table 1 and Figure S1. The samples comprised 20 olive oil cultivars, 3 table olive cultivars, and 7 olive cultivars which could be used for both olive oil extraction and table olive production. The samples also included two rootstock autochthonous cultivars: OL20 (O. europaea subsp. Cuspidata isolate Yunnan) and OL27 (Zhonglan). We classified all 32 olive cultivars into high-oil-content (>20\%), medium-oil-content (16-20\%) and low-oilcontent $(<16 \%)$ cultivars, according to the database (URL: www.oleadb.it, accessed on 25 January 2022) and our own data.

The olive leaf samples were manually picked between mid-November and midDecember 2020. The moisture contents of the olive leaf samples ranged from $43.27 \%$ for OL27 (Largueta cultivar) to 58.59\% for OL31 (Morcona cultivar; Table 1), according to the Chinese National Standard GB5009.3-2016 (Determination of water in foods). The fresh olive leaves were oven-dried at $105{ }^{\circ} \mathrm{C}$ until a safe storage moisture content was reached. The dried leaves were then ground using a grinder, passed through a 60-mesh $(250 \mu \mathrm{m})$ sieve to obtain a fine powder, and then stored in vacuum-sealed bags at $-20{ }^{\circ} \mathrm{C}$ until extraction.

\subsection{Sample Extraction}

The dried olive leaf powder $(1.00 \mathrm{~g} \pm 0.01 \mathrm{~g})$ from each cultivar was fully mixed with $10 \mathrm{~mL}$ of $70 \%$ ethanol solution and then extracted under continuous sonication $(40 \mathrm{kHz})$ for $30 \mathrm{~min}$ at $50{ }^{\circ} \mathrm{C}$. The leaf extracts were centrifuged at $5000 \mathrm{rpm}$ for $10 \mathrm{~min}$, and the supernatant was collected. The extraction processes were repeated three times. All supernatants were combined and diluted to $50 \mathrm{~mL}$. Then, the total flavonoid content (TFC), total phenolic content (TPC), and antioxidant activities of the extracts were determined. Prior to phytochemical profile analyses, the extracts were filtered with a $0.22 \mu \mathrm{m}$ syringe filter. 
Table 1. Summary of the 32 olive cultivars used in this study.

\begin{tabular}{|c|c|c|c|c|c|}
\hline Code & Cultivar & Origin & Moisture Content $\%$ & Attitude & Oil Content \\
\hline OL1 & Bouteillan & France & $45.05 \pm 1.76^{\mathrm{ab}}$ & $\mathrm{O} / \mathrm{T}$ & $\mathrm{H}$ \\
\hline OL2 & Fecciaro & Italy & $54.83 \pm 2.25 \mathrm{kl}$ & $\mathrm{O}$ & $\mathrm{L}$ \\
\hline OL3 & Frantoio selection & China & $47.71 \pm 1.20 \mathrm{de}$ & $\mathrm{O}$ & $\mathrm{L}$ \\
\hline OL4 & Manzanilla & Italy & $47.16 \pm 1.36^{\text {cde }}$ & $\mathrm{T}$ & $\mathrm{L}$ \\
\hline OL5 & Nocellara del belice & Italy & $54.77 \pm 1.38^{\mathrm{kl}}$ & $\mathrm{O} / \mathrm{T}$ & M \\
\hline OL6 & Picudo de Labata & Spain & $44.66 \pm 1.29 \mathrm{ab}$ & $\mathrm{O}$ & $\mathrm{H}$ \\
\hline OL7 & $\mathrm{I}-79$ & Italy & $50.45 \pm 1.56^{\mathrm{fg}}$ & $\mathrm{O}$ & $\mathrm{L}$ \\
\hline OL8 & Pendolino & Italy & $56.56 \pm 0.31 \mathrm{~lm}$ & $\mathrm{O}$ & M \\
\hline OL9 & $\begin{array}{l}\text { O. europaea subsp. Cuspidata } \\
\text { isolate Yunnan }\end{array}$ & China & $48.84 \pm 0.83$ ef & $\mathrm{R}$ & $\mathrm{L}$ \\
\hline OL10 & Ascolana tenera & Italy & $57.81 \pm 2.26^{n}$ & $\mathrm{~T}$ & M \\
\hline OL11 & Zhonglan & China & $48.23 \pm 1.88$ ef & $\mathrm{R}$ & $\mathrm{L}$ \\
\hline OL12 & Koroneiki & Greece & $52.12 \pm 1.12^{\mathrm{ij}}$ & $\mathrm{O}$ & $\mathrm{L}$ \\
\hline OL13 & Arbequina & Spain & $52.33 \pm 1.30 \mathrm{ij}$ & $\mathrm{O}$ & M \\
\hline OL14 & Huaou 5 & China & $52.04 \pm 0.50^{\mathrm{ij}}$ & $\mathrm{O}$ & $\mathrm{L}$ \\
\hline OL15 & Nikitskii I & Azerbaijan & $52.16 \pm 1.79 \mathrm{ij}$ & $\mathrm{O} / \mathrm{T}$ & $\mathrm{H}$ \\
\hline OL16 & Picholine & France & $51.08 \pm 0.97 \mathrm{gh}$ & $\mathrm{O} / \mathrm{T}$ & M \\
\hline OL17 & Chemlal de Kabylie & Algeria & $49.02 \pm 0.60^{\text {efg }}$ & $\mathrm{O}$ & $\mathrm{L}$ \\
\hline OL18 & Hojiblanca & Spain & $46.76 \pm 2.50^{b c}$ & $\mathrm{O} / \mathrm{T}$ & $\mathrm{H}$ \\
\hline OL19 & Manzanilla sevillana & Spain & $43.76 \pm 0.86^{\mathrm{a}}$ & $\mathrm{T}$ & $\mathrm{L}$ \\
\hline OL20 & Canino & Italy & $53.75 \pm 1.35^{\mathrm{jk}}$ & $\mathrm{O}$ & M \\
\hline OL21 & Cipressino & Italy & $55.12 \pm 0.80 \mathrm{kl}$ & $\mathrm{O}$ & M \\
\hline OL22 & Rosciola & Italy & $57.23 \pm 1.02 \mathrm{mn}$ & $\mathrm{O}$ & $\mathrm{H}$ \\
\hline OL23 & Nevadillo fino & Spain & $51.31 \pm 0.31$ hij & $\mathrm{O}$ & $\mathrm{H}$ \\
\hline OL24 & Castellana & Spain & $51.30 \pm 1.20$ hij & $\mathrm{O}$ & M \\
\hline OL25 & Neral & Spain & $53.72 \pm 0.77^{\mathrm{jk}}$ & $\mathrm{O}$ & M \\
\hline OL26 & Olivon de Roda & Spain & $47.89 \pm 0.63^{\mathrm{e}}$ & $\mathrm{O}$ & $\mathrm{H}$ \\
\hline OL27 & Largueta & Spain & $43.27 \pm 1.74^{\mathrm{a}}$ & $\mathrm{O}$ & M \\
\hline OL28 & Manzanilla Greece & Spain & $45.53 \pm 0.59 \mathrm{ab}$ & $\mathrm{O} / \mathrm{T}$ & $\mathrm{L}$ \\
\hline OL29 & Blanqueta & Spain & $54.80 \pm 0.82^{\mathrm{kl}}$ & $\mathrm{O}$ & $\mathrm{H}$ \\
\hline OL30 & Benizar & Spain & $51.66 \pm 1.35 \mathrm{ij}$ & $\mathrm{O} / \mathrm{T}$ & $\mathrm{H}$ \\
\hline OL31 & Morcona & Italy & $58.59 \pm 0.42^{n}$ & $\mathrm{O}$ & M \\
\hline OL32 & Gentile di chieti & Italy & $58.23 \pm 0.61^{n}$ & $\mathrm{O}$ & M \\
\hline
\end{tabular}

O: olive oil cultivars; T: table olive cultivars; O/T: olive cultivars that can be used in both olive oil extraction and table olive production; R: rootstock cultivars; $\mathrm{H}, \mathrm{M}$, and $\mathrm{L}$ represent high-oil-content $(>20 \%)$ olive cultivars, medium-oil-content (16-20\%) olive cultivars, and low-oil-content $(<16 \%)$ olive cultivars, respectively; ${ }^{\mathrm{a}-\mathrm{n}}$ Means in the same column with unlike superscripts differ significantly $(p<0.05)$.

\subsection{Phytochemical Profiling}

2.4.1. Identification of the Phytochemical Compounds via HPLC-Electrospray Ionization-Tandem Mass Spectrometry

The phytochemical compounds in the olive leaves were identified using an Agilent 1200LC system coupled with a Thermo Finnigan LCQ DECA mass spectrometer equipped with an electrospray source. Chromatographic separation was performed using a ZORBAX SB-C18 column $(4.6 \times 250 \mathrm{~mm}, 5 \mu \mathrm{m}$, Agilent Technologies, Savage, MD, USA $)$ at a flow rate of $1.0 \mathrm{~mL} / \mathrm{min}$. The mobile phases were acetic acid $(1 \%) /$ deionized water (mobile phase A) and acetic acid (1\%)/acetonitrile (mobile phase B). The elution conditions were as follows: $0-11 \mathrm{~min}, 10-25 \% \mathrm{~B} ; 11-16 \mathrm{~min}, 25-28.5 \% \mathrm{~B} ; 16-40 \mathrm{~min}, 28.5-90 \% \mathrm{~B}$; $40-50 \mathrm{~min}, 90 \% \mathrm{~B} ; 50-55 \mathrm{~min}, 90-10 \% \mathrm{~B}$; and $55-60 \mathrm{~min}, 10 \% \mathrm{~B}$. The flow rate was $1 \mathrm{~mL} / \mathrm{min}$. Analyses were performed with scans from $\mathrm{m} / \mathrm{z} 125$ to $1200 \mathrm{Da}$ in negative and positive ion modes. The peaks were identified using an Xcalibur Qual Browser by comparing the molecular ions, fragmentation, and relative retention times with the literature data and reference compounds. 


\subsubsection{Quantification of Individual Phenolics by HPLC Coupled with Diode} Array Detection

Individual phenolic compounds were quantitatively analyzed using a ZORBAX SBC18 column $(4.6 \times 250 \mathrm{~mm}, 5 \mu \mathrm{m})$ in a Shimadzu LC-2030C HPLC system (Kyoto, Japan). The elution conditions were the same as those used for qualitative analysis, and the peaks were detected at 254,280 , and $320 \mathrm{~nm}$. The peaks were then quantitatively analyzed by LabSolutions HPLC software using the calibration curves of the corresponding standards or a compound that contained a similar aglycone. The phenolics standards were dissolved in $80 \%$ methanol to obtain a concentration of approximately $1.0 \mathrm{mg} / \mathrm{mL}$. The standard solution mixture was divided into five gradients using an approximately two-fold dilution process, and the five gradients were then used to prepare the calibration standards. Chromatographic separation was the same as the process used for the olive extracts.

\subsubsection{Quantification of Triterpenic Acids by HPLC Coupled with Diode Array Detection}

The standards of asiatic acid, oleanonic acid, maslinic acid, corosolic acid, oleanolic acid, and ursolic acid were dissolved in $80 \%$ methanol to obtain a concentration of approximately $1.0 \mathrm{mg} / \mathrm{mL}$. The standard solution mixture was then divided into five gradients using an approximately two-fold dilution process; the gradients were then used for the preparation of the calibration standards. The triterpene concentrations in the olive leaves were determined using a Shimadzu LC-2030C HPLC system coupled with a ZORBAX SB-C18 column. The mobile phases were acetic acid (1\%)/deionized water (phase A) and acetic acid (1\%)/acetonitrile (phase B), and the isocratic elution flow rates were $9 \%(A)$ and $91 \%$ (B). Then, the absorbance at $210 \mathrm{~nm}$ was detected. The spectral peaks were quantitatively analyzed with LabSolutions HPLC software using the calibration curves of the corresponding standards.

\subsection{TFC}

The TFC in the olive leaves was determined according to the aluminum chloride colorimetric method, using rutin as the standard [24]. First, $1 \mathrm{~mL}$ of the extracted samples was transferred into a $10 \mathrm{~mL}$ calibrated test tube, and $0.4 \mathrm{~mL}$ of $5 \%$ sodium nitrite solution was added. Then, the mixture was shaken for effective mixing and left to stand for $6 \mathrm{~min}$. Afterward, $0.4 \mathrm{~mL}$ of $10 \%$ aluminum nitrate solution was added to the mixture. Then, the mixture was shaken and left to stand for $6 \mathrm{~min}$. Finally, $4 \mathrm{~mL}$ of $5 \%$ sodium hydroxide solution and $10 \mathrm{~mL}$ of water were successively added to the mixture, and the mixture was shaken and left to stand for $15 \mathrm{~min}$. Afterward, the absorbance value at $510 \mathrm{~nm}$ was measured. The TFC is expressed as $\mathrm{mg}$ rutin equivalent per gram of dry weight (mg RE/g dw).

\subsection{TPC}

The TPC was assessed according to the Folin-Ciocalteu method, using gallic acid as the standard [25]. First, $0.4 \mathrm{~mL}$ of each extract was transferred into a $25 \mathrm{~mL}$ graduated test tube, and $1 \mathrm{~mL}$ of the Folin-Ciocalteu reagent was added. After the mixture was shaken for effective mixing, the reagent was left to stand for 3-4 min. Then, $5 \mathrm{~mL}$ of $7.5 \%$ sodium carbonate solution was added, followed by distilled water, which was added to the different mixtures to achieve a constant volume of $25 \mathrm{~mL}$. The mixtures were bathed in water at $40{ }^{\circ} \mathrm{C}$ for $30 \mathrm{~min}$, and the absorbance at $765 \mathrm{~nm}$ was measured. The TPC is expressed as mg gallic acid equivalent per gram of dry weight (mg GAE/g dw).

\subsection{Antioxidant Activity}

The antioxidant activity of the olive leaf extracts was determined by the standard DPPH, ABTS, and ferric reducing/antioxidant power (FRAP) assays according to the methods established by Martinović and Cavoski [26] with some minor modifications. The results were calculated from the Trolox calibration curve and are expressed as mg Trolox equivalent per gram of dry weight (mg TE/g dw). 
For the DPPH free radical scavenging assay, $0.1 \mathrm{~mL}$ of each extract was transferred into a test tube, and $3.9 \mathrm{~mL}$ of $0.1 \mathrm{mmol} / \mathrm{L} \mathrm{DPPH}$ reaction solution was added. The reaction proceeded in the dark for $30 \mathrm{~min}$. Then, the absorbance at $517 \mathrm{~nm}$ was measured.

For the ABTS assay, ABTS stock solutions including $7 \mathrm{mM}$ ABTS and potassium persulfate $\left(\mathrm{K}_{2} \mathrm{~S}_{2} \mathrm{O}_{8}, 2.45 \mathrm{mM}\right)$ were prepared. The ABTS stock solution was diluted with ethanol to obtain an absorbance of $0.70 \pm 0.02$ at $734 \mathrm{~nm}$. Then, $3.9 \mathrm{~mL}$ of ABTS+ working solution and $0.1 \mathrm{~mL}$ of extracts were mixed for $6 \mathrm{~min}$ in the dark. Afterward, the absorbance was measured at $734 \mathrm{~nm}$ relative to the reagent blank (ethanol).

For the FRAP assay, $300 \mathrm{mM}$ acetate buffer (pH 3.6), $10 \mathrm{mM}$ TPTZ solution in $40 \mathrm{mmol} / \mathrm{L} \mathrm{HCl}$, and $20 \mathrm{mM}$ ferric chloride were mixed at a ratio of 10:1:1 to prepare the FRAP reagent. Subsequently, $0.5 \mathrm{~mL}$ of extracts and $4.5 \mathrm{~mL}$ of FRAP reagent were transferred into a vial and incubated at $37^{\circ} \mathrm{C}$ for $30 \mathrm{~min}$. Then, the absorbance was measured at $593 \mathrm{~nm}$.

\subsection{Statistical Analysis}

All experiments were conducted at least three times, and the results are expressed as mean \pm standard deviation. Statistical analyses were performed using IBM SPSS Software 21 (Chicago, IL, USA). The parametric analysis of variance (ANOVA) was conducted by multifactor analysis of variance and post hoc Duncan's multiple range test, where $p<0.05$ was considered significant. Pearson's correlation scatter plots between antioxidant activity (DPPH, ABTS, and FRAP), TPC, and TFC were constructed using GraphPad Software 7 (San Diego, CA, USA). The relationships between the concentrations of the 32 phenolics and 5 variables (TPC, TFC, DPPH, ABTS, and FRAP) were obtained using Spearman's rank correlations, and a correlation heatmap was obtained using the vegan package in $R$ software (version 3.1.2). Principal component analysis (PCA) was conducted on the mean values of the 32 phenolics and 5 variables (TPC, TFC, DPPH, ABTS, and FRAP) using SIMCA-P software (Umetrics, Umea, Sweden).

\section{Results and Discussion}

\subsection{Identification and Quantification of Phytochemical Compounds}

In this study, 32 phytochemical compounds were identified (Table 2 and Figure 1), consisting of flavonoids (17), iridoids (5), hydroxycinnamic acids (2), triterpenic acids (6), simple phenols (1), and coumarins (1). The identified phytochemical compounds showed no differences among the 32 cultivars. Most of the reported data on olive leaves indicated that phenolics are the major biologically active compounds in olive leaves $[1,12]$. In recent decades, these compounds have attracted attention for human health purposes, due to their notable antioxidant activities through single-electron and hydrogen atom transfer [27]. The phenolic profiles of olive leaves previously detected in several common cultivars, such as Negrinha do Freixo, Hojiblanca, and Cornicabra, were slightly different from those identified in this work; however, the major class of phenolics (i.e., flavonoids, iridoids, simple phenols) exhibited the same profiles as those reported in the literature $[28,29]$.

\subsubsection{Flavonoid Derivatives}

Flavonoids represent one of the most diverse groups of phenolic compounds in olive leaves [28]. Plant-based flavonoids have strong antioxidant, antimicrobial, and anti-hyperglycemic potentials because of their ability to scavenge free radicals, kill many bacterial strains, and inhibit starch-digesting enzymes [33]. Our results showed that most of the flavonoids occurred in glycosylated forms in the olive leaves (e.g., luteolin-3', 7 -diO-glucoside, rutin, luteolin rutinoside, luteolin-7-O-glucoside, kaempferol-7-O-glucoside, quercetin-3-O-glucoside, taxifolin-3-glucoside, and apigenin-7-O-neohesperidoside). Moreover, six flavonoids were in the form of aglycones (i.e., luteolin, quercetin, taxifolin, eriodictyol, kaempferol, and hispidulin). The total quantities of glycosylated flavonoids (4.58-17.26 mg/g dw) were approximately 10 times those of the corresponding flavonoid aglycones (0.34-2.28 mg/g dw; Table S1). 
Table 2. Characterization of phenolic compounds from olive leaves via HPLC-ESI-MS.

\begin{tabular}{|c|c|c|c|c|c|c|c|}
\hline No. & Proposed Compounds & Rt min & Molecular Formula & Ionization (ESI+/ESI - ) & $m / z$ Experimental & Class & Reference \\
\hline 1 & Loganic acid & 4.28 & $\mathrm{C}_{16} \mathrm{H}_{24} \mathrm{O}_{10}$ & {$[\mathrm{M}-\mathrm{H}]-$} & 375.1 & Iridoids & Alañón et al., 2020 [29] \\
\hline 2 & Hydroxytyrosol & 5.543 & $\mathrm{C}_{8} \mathrm{H}_{10} \mathrm{O}_{3}$ & {$[\mathrm{M}-\mathrm{H}]-$} & 153.1 & Simple phenols & Standard \\
\hline 3 & Esculin & 6.14 & $\mathrm{C}_{15} \mathrm{H}_{16} \mathrm{O}_{9}$ & {$[\mathrm{M}-\mathrm{H}]-$} & 339.2 & Coumarins & Standard \\
\hline 4 & Taxifolin-3-glucoside & 6.451 & $\mathrm{C}_{21} \mathrm{H}_{22} \mathrm{O}_{12}$ & {$[\mathrm{M}-\mathrm{H}]-$} & 465.2 & Flavonoids & Abaza et al., 2017 [30] \\
\hline 5 & Chlorogenic acid & 7.003 & $\mathrm{C}_{16} \mathrm{H}_{18} \mathrm{O}_{9}$ & {$[\mathrm{M}-\mathrm{H}]-$} & 353.2 & Hydroxycinnamic acid & Standard \\
\hline 6 & Secoxyloganin & 8.359 & $\mathrm{C}_{17} \mathrm{H}_{24} \mathrm{O}_{11}$ & {$[\mathrm{M}-\mathrm{H}]-$} & 403.2 & Iridoids & Standard \\
\hline 7 & Luteolin-3',7-di-O-glucoside & 9.069 & $\mathrm{C}_{27} \mathrm{H}_{30} \mathrm{O}_{16}$ & [M-H]- & 609.1 & Flavonoids & Alañón et al., 2020 [29] \\
\hline 8 & Plantamajoside & 9.55 & $\mathrm{C}_{29} \mathrm{H}_{36} \mathrm{O}_{16}$ & {$[\mathrm{M}-\mathrm{H}]-$} & 639.3 & Hydroxycinnamic acid & Standard \\
\hline 10 & Luteolin rutinoside & 11.767 & $\mathrm{C}_{27} \mathrm{H}_{30} \mathrm{O}_{15}$ & {$[\mathrm{M}-\mathrm{H}]-$} & 593.3 & Flavonoids & Alañón et al., 2020 [29] \\
\hline 11 & Quercetin-3-O-glucoside & 12.342 & $\mathrm{C}_{21} \mathrm{H}_{20} \mathrm{O}_{12}$ & {$[\mathrm{M}-\mathrm{H}]-$} & 463.2 & Flavonoids & Standard \\
\hline 12 & Luteolin-7-O-glucoside & 12.613 & $\mathrm{C}_{21} \mathrm{H}_{20} \mathrm{O}_{11}$ & {$[\mathrm{M}-\mathrm{H}]-$} & 447.4 & Flavonoids & Standard \\
\hline 13 & Apigenin-7-O-neohesperidoside & 13.546 & $\mathrm{C}_{27} \mathrm{H}_{30} \mathrm{O}_{14}$ & {$[\mathrm{M}-\mathrm{H}]-$} & 577.3 & Flavonoids & Standard \\
\hline 14 & Taxifolin & 13.793 & $\mathrm{C}_{15} \mathrm{H}_{12} \mathrm{O}_{7}$ & {$[\mathrm{M}-\mathrm{H}]-$} & 303.3 & Flavonoids & Standard \\
\hline 15 & Quercetin 3-O-rhamnoside & 14.347 & $\mathrm{C}_{21} \mathrm{H}_{20} \mathrm{O}_{11}$ & {$[\mathrm{M}-\mathrm{H}]-$} & 447.2 & Flavonoids & Vinha et al., 2005 [31] \\
\hline 16 & Apigenin-7-O-glucoside & 14.47 & $\mathrm{C}_{21} \mathrm{H}_{20} \mathrm{O}_{10}$ & {$[\mathrm{M}-\mathrm{H}]-$} & 431.4 & Flavonoids & Alañón et al., 2020 [30] \\
\hline 17 & Kaempferol-7-O-glucoside & 14.697 & $\mathrm{C}_{21} \mathrm{H}_{20} \mathrm{O}_{11}$ & {$[\mathrm{M}-\mathrm{H}]-$} & 447.2 & Flavonoids & Standard \\
\hline 18 & Luteolin-4'-O-glucoside & 15.733 & $\mathrm{C}_{21} \mathrm{H}_{20} \mathrm{O}_{11}$ & {$[\mathrm{M}-\mathrm{H}]-$} & 447.3 & Flavonoids & Abaza et al., 2017 [30] \\
\hline 21 & Oleuropein isomer 3 & 17.647 & $\mathrm{C}_{25} \mathrm{H}_{32} \mathrm{O}_{13}$ & {$[\mathrm{M}-\mathrm{H}]-$} & 539.2 & Iridoids & Abaza et al., 2017 [30] \\
\hline 22 & Eriodictyol & 20.765 & $\mathrm{C}_{15} \mathrm{H}_{12} \mathrm{O}_{6}$ & {$[\mathrm{M}-\mathrm{H}]-$} & 287.1 & Flavonoids & Standard \\
\hline 23 & Luteolin & 21.133 & $\mathrm{C}_{15} \mathrm{H}_{10} \mathrm{O}_{6}$ & {$[\mathrm{M}-\mathrm{H}]-$} & 285.5 & Flavonoids & Standard \\
\hline 24 & Quercetin & 21.35 & $\mathrm{C}_{15} \mathrm{H}_{10} \mathrm{O}_{7}$ & {$[\mathrm{M}-\mathrm{H}]-$} & 301.3 & Flavonoids & Standard \\
\hline 25 & Kaempferol & 24.85 & $\mathrm{C}_{15} \mathrm{H}_{10} \mathrm{O}_{6}$ & {$[\mathrm{M}-\mathrm{H}]-$} & 285.4 & Flavonoids & Standard \\
\hline 26 & Hispidulin & 27.701 & $\mathrm{C}_{16} \mathrm{H}_{12} \mathrm{O}_{6}$ & {$[\mathrm{M}-\mathrm{H}]-$} & 299.3 & Flavonoids & Blasi et al., 2018 [32] \\
\hline 27 & Asiatic acid & 38.11 & $\mathrm{C}_{30} \mathrm{H}_{48} \mathrm{O}_{5}$ & {$[\mathrm{M}-\mathrm{H}]-$} & 487.3 & Triterpenic acids & Standard \\
\hline 28 & Oleanonic acid & 38.71 & $\mathrm{C}_{30} \mathrm{H}_{46} \mathrm{O}_{3}$ & {$[\mathrm{M}+\mathrm{H}]+$} & 455.3 & Triterpenic acids & Standard \\
\hline 29 & Maslinic acid & 39.64 & $\mathrm{C}_{30} \mathrm{H}_{48} \mathrm{O}_{4}$ & {$[\mathrm{M}+\mathrm{H}]+$} & 473.5 & Triterpenic acids & Standard \\
\hline 30 & Corosolic acid & 40.19 & $\mathrm{C}_{30} \mathrm{H}_{48} \mathrm{O}_{4}$ & {$[\mathrm{M}+\mathrm{H}]+$} & 473.2 & Triterpenic acids & Standard \\
\hline 31 & Oleanolic acid & 44.61 & $\mathrm{C}_{30} \mathrm{H}_{48} \mathrm{O}_{3}$ & {$[\mathrm{M}-\mathrm{H}]-$} & 457.5 & Triterpenic acids & Standard \\
\hline 32 & Ursolic acid & 44.33 & $\mathrm{C}_{30} \mathrm{H}_{48} \mathrm{O}_{3}$ & {$[\mathrm{M}+\mathrm{H}]+$} & 457.3 & Triterpenic acids & Standard \\
\hline
\end{tabular}

Rt: retention time. 

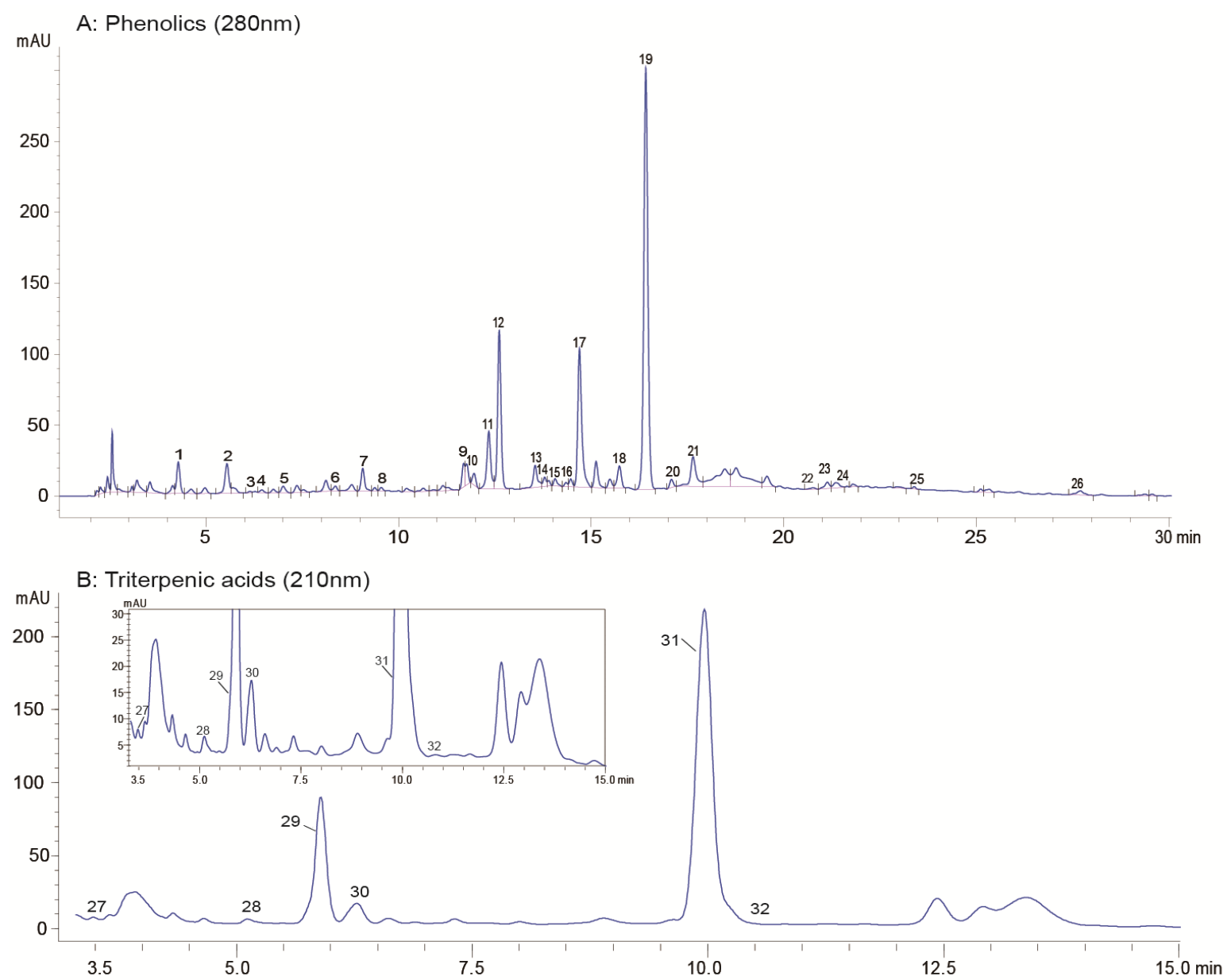

Figure 1. HPLC base peak chromatograms of the olive leaf extracts: (A) phenolics: (1) loganic acid; (2) hydroxytyrosol; (3) esculin; (4) taxifolin-3-glucoside; (5) chlorogenic acid; (6) secoxyloganin; (7) luteolin-3',7-di-O-glucoside; (8) plantamajoside; (9) rutin; (10) luteolin rutinoside; (11) quercetin3-O-glucoside; (12) luteolin-7-O-glucoside; (13) apigenin-7-O-neohesperidoside; (14) taxifolin; (15) quercetin 3-O-rhamnoside; (16) apigenin-7-O-glucoside; (17) kaempferol-7-O-glucoside; (18) luteolin-4'-O-glucoside; (19) oleuropein isomer 1; (20) oleuropein isomer 2; (21) oleuropein isomer 3; (22) eriodictyol; (23) luteolin; (24) quercetin; (25) kaempferol; (26) hispidulin; (B) triterpenic acids: (27) asiatic acid; (28) oleanonic acid; (29) maslinic acid; (30) corosolic acid; (31) oleanolic acid; and (32) ursolic acid.

According to previous studies, flavonoid expression in olives leaves was predominately driven by genetic and environmental factors [28], and the results of this study showed considerable differences among the cultivars. In all studied cultivars, luteolin-7-Oglucoside and kaempferol-7-O-glucoside were the most abundant flavonoids, with quantities of 1.20-7.00 and 1.49-5.32 mg/g dw, respectively; they were most abundant in cultivar OL10 (Ascolana tenera) and least abundant in OL1 (Bouteillan). Other abundant flavonoids included rutin, which was the most abundant in OL12 (Koroneiki, $1.48 \mathrm{mg} / \mathrm{g} \mathrm{dw}$ ), OL5 (Nocellara del belice, $1.45 \mathrm{mg} / \mathrm{g} \mathrm{dw}$ ), and quercetin-3-O-glucoside, which was most abundant in OL5 (1.14 mg/g dw) and OL7 (I-79, $1.12 \mathrm{mg} / \mathrm{g} \mathrm{dw})$. Further analysis was conducted from the oil content viewpoint, which has been one of the most important economic factors for the characterization of olive cultivars [22,23], in order to discriminate between the different cultivars. As shown in Figure 2A, the mean total quantities of flavonoids (TQFs) in the leaves of the olive cultivars with high, medium, and low oil contents were 9.07, 12.69 , and $14.07 \mathrm{mg} / \mathrm{g} \mathrm{dw}$, respectively. Overall, six varieties with low or medium oil content showed relatively higher TQF values (>15 mg/g dw), namely, OL5 (M, 18.29 mg/g $\mathrm{dw}$ ), OL9 (L, O. europaea subsp. Cuspidata isolate Yunnan, $16.81 \mathrm{mg} / \mathrm{g} \mathrm{dw}$ ), OL10 (M, 
$15.97 \mathrm{mg} / \mathrm{g} \mathrm{dw}$ ), OL2 (L, Fecciaro, $15.68 \mathrm{mg} / \mathrm{g} \mathrm{dw}$ ), OL7 (L, $15.39 \mathrm{mg} / \mathrm{g} \mathrm{dw}$ ), and OL11 (L, Zhonglan, $15.26 \mathrm{mg} / \mathrm{g} \mathrm{dw}$ ). However, the high-oil-content cultivar, OL1, exhibited the lowest TQF value at only $4.92 \mathrm{mg} / \mathrm{g} \mathrm{dw}$. In the present study, we assessed olive cultivars from both oil contents and useful by-products, simultaneously. Anastasiu et al. also proposed a selection criterion based on both oil productivity and the oil iodine value for linseed (Linum usitatissimum L.) which proved highly efficient to rank linseed cultivars from both a quantitative and qualitative viewpoint [34]. Consequently, cultivar evaluation from different viewpoints in a simultaneous manner may provide novel ideas for the efficient utilization of agricultural resources.

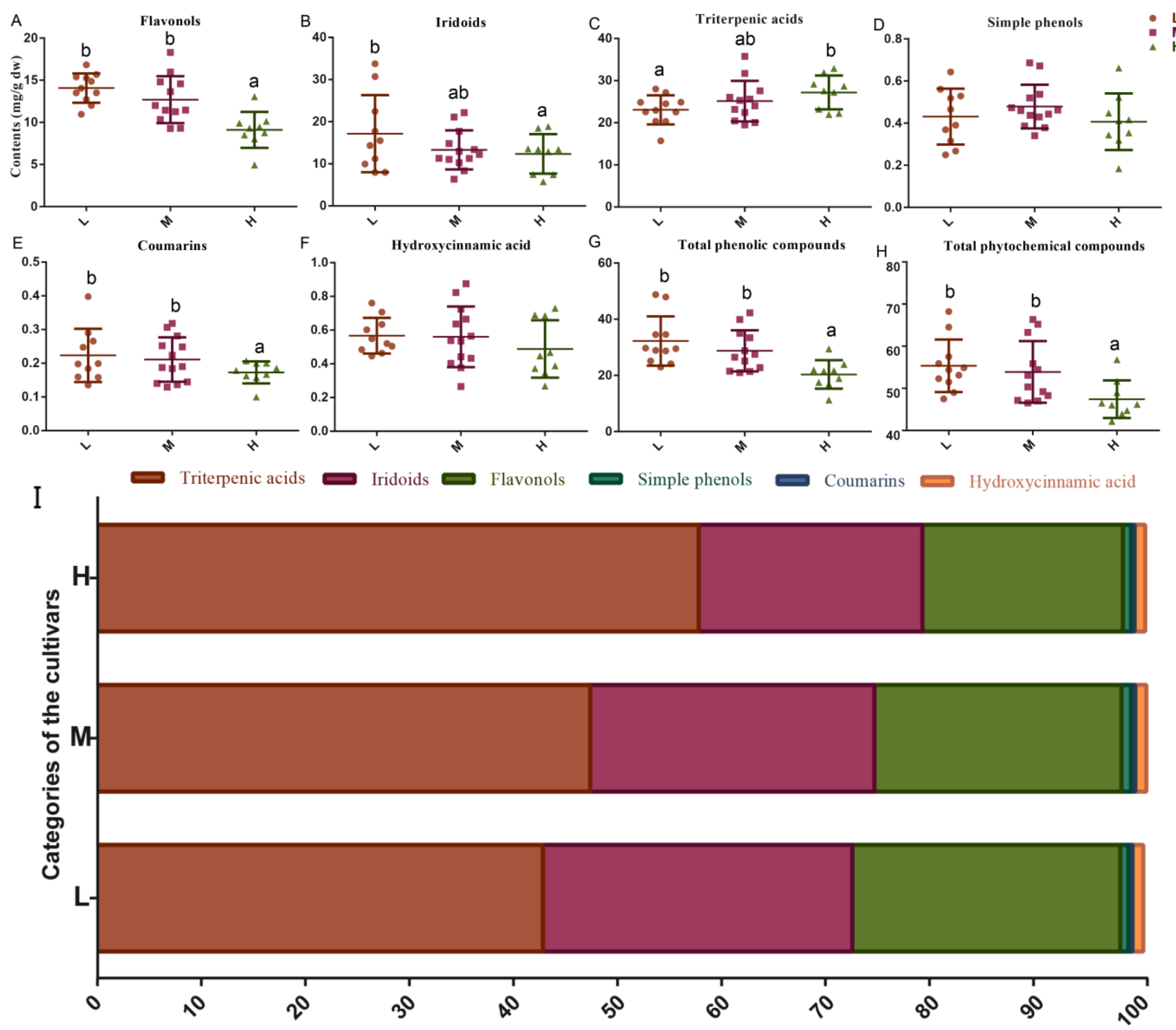

Figure 2. Compositions of the total quantity of (A) flavonols, (B) iridoids, (C) triterpenic acids, (D) simple phenols, (E) coumarins, (F) hydroxycinnamic acid, (G) total phenolic compounds, and (H) total phytochemical compounds in the olive leaf extracts from 32 cultivars and (I) distribution of the corresponding total content of the six phytochemicals in each category. For each category, the different letters indicate a significant difference $(p<0.05)$. H, M, and L represent high-oil-content ( $>20 \%$ ) olive cultivars, medium-oil-content (16-20\%) olive cultivars, and low-oil-content $(<16 \%)$ olive cultivars, respectively. 


\subsubsection{Iridoid Derivatives}

Five iridoid compounds were identified: loganic acid, secoxyloganin, and oleuropein and its isomers. Iridoids and their related subclass secoiridoids are rarely found in edible plants; however, they have been frequently reported as a major class of phenolics in olive fruits and leaves [3]. Furthermore, most of the observed antimicrobial, antiviral, antioxidant, antihypertensive, and antitumoral properties of olive leaf extracts have been attributed to secoiridoids, particularly oleuropein [1]. Oleuropein and its isomers were the predominant polyphenols in all studied cultivars (Table S2), especially in the two autochthonous cultivars (OL3 [Frantoio selection] and OL9: 32.05 and $29.27 \mathrm{mg} / \mathrm{g} \mathrm{dw}$, respectively), whose oleuropein concentrations were approximately six times those of the cultivars with the lowest oleuropein concentrations (OL1 and OL26 [Olivon de Roda]: 5.21 and $5.25 \mathrm{mg} / \mathrm{g} \mathrm{dw}$, respectively). Moreover, loganic acid and secoxyloganin were also abundant in all cultivars, and they were most abundant in OL24 (Castellana, $1.23 \mathrm{mg} / \mathrm{g} \mathrm{dw}$ ) and OL5 $(1.69 \mathrm{mg} / \mathrm{g} \mathrm{dw})$, respectively. Similarly, iridoid compound content varied greatly among the three categories in terms of oil content (Figure 2B, $p<0.05$ ). The cultivars with high oil content had the lowest total iridoid content of $10.22 \mathrm{mg} / \mathrm{g} \mathrm{dw}$, while the cultivars with low oil content had the highest value of $16.88 \mathrm{mg} / \mathrm{g} \mathrm{dw}$. Cecchi et al. also found that the oil content and oleuropein quantity during ripening were cultivar-dependent, but they did not highlight strong correlations between the oil content and phenolic compounds [35].

\subsubsection{Terpene Derivatives}

In addition to flavanols and iridoids, triterpenic acids (i.e., asiatic, oleanonic, maslinic, corosolic, oleanolic, and ursolic acid) have also been found to be a major class of bioactive compounds in olive leaves. Table olives and olive oil have been reported to be rich in maslinic and oleanolic acids, and small quantities of ursolic acid have been detected in olive oils $[16,36]$. In olive products, the maslinic acid concentration ranges from $287.1 \pm 66.6$ in the Manzanilla variety, $1318.4 \pm 401.0 \mathrm{mg} / \mathrm{kg}$ in Arbequina table olives, and from $64.2 \pm 8.1$ to $193.9 \pm 14.0 \mathrm{mg} / \mathrm{kg}$ in olive oils [37]. Despite the presence of triterpenic acids in olive fruits, data on the quantities of these substances in olive leaves are scarce. In this study, we showed the presence of important levels of triterpenic acids in olive leaves. The overall concentration of triterpenic acids ranged from $15.72 \mathrm{mg} / \mathrm{g} \mathrm{dw}$ (OL9; Table S2) to $35.75 \mathrm{mg} / \mathrm{g} \mathrm{dw}$ (OL16, Picholine), and maslinic and oleanolic acids were more abundant than asiatic, oleanonic, corosolic, and ursolic acids in all of the studied varieties. Unlike flavonoids and iridoids, the leaves of olive cultivars with high oil content contained significantly higher mean triterpenic acid content $(27.19 \mathrm{mg} / \mathrm{g} \mathrm{dw})$ than the other two categories ( 25.14 and $23.08 \mathrm{mg} / \mathrm{g} \mathrm{dw}$ for medium- and low-oil-content cultivars, respectively; Figure 2C). In addition, triterpenic acids were the dominant phytochemicals (accounting for $57.65 \%$ ) in the olive leaves of the high-oil-content categories (Figure 2I). These results suggested that cultivars with high oil content could be a good choice for the extraction of triterpenic acids, which could serve as potential nutraceuticals for valorizing olive leaves. Recently, triterpenic acids, especially oleanolic and maslinic acids, were demonstrated to possess multiple health-protective activities, including anti-diabetic, anti-inflammatory, cardioprotective, and anti-tumoral properties [36,38].

\subsubsection{Simple Phenol, Coumarins, and Hydroxycinnamic Acids}

We identified one simple phenol (hydroxytyrosol), one coumarin (esculin), and two hydroxycinnamic acids (plantamajoside and chlorogenic acid) in the olive leaf extracts of all the studied varieties. Previous research has also identified coumarins and hydroxycinnamic acids in olive leaves [39]. Not only was hydroxytyrosol the main simple phenol in olive leaves, but it was also vital for secoiridoid formation [1]; its concentration ranged from 0.18 to $0.69 \mathrm{mg} / \mathrm{g} \mathrm{dw}$. Additionally, the hydroxytyrosol, esculin, plantamajoside, and chlorogenic acid contents in the different cultivars varied greatly (Table S2); however, the differences between the three categories were not significant (Figure 2D-F). 


\subsection{TPC, TFC, and Antioxidant Activities}

TPC and TFC evaluation is a rapid, sensitive, and robust method for assessing the quantitative composition of biologically active compounds. The TFC and TPC of the olive leaves were determined through the aluminum chloride colorimetric method and FolinCiocalteu assay. No significant differences in the TPC and TFC were found among the three categories in terms of oil content (Figure S2A,B), even though substantial changes were found among the different cultivars. As shown in Table 3, the leaves of the 32 olive cultivars exhibited slight differences in TPC, ranging from $15.13 \pm 0.19$ to $17.49 \pm 0.12 \mathrm{mg} \mathrm{GAE} / \mathrm{g}$ dw. OL31 (Morcona) exhibited the highest TPC value in the leaf extracts, followed by OL32 (Gentile di chieti), OL4 (Manzanilla), and OL20 (Canino), whereas OL23 (Nevadillo fino) exhibited the lowest TPC value. Gullon et al. reported a TPC of $12.36-27.54 \mathrm{mg} / \mathrm{g}$ in dried olive mill leaves [40]. Thus, the TPC values obtained in this study were within the literature-reported range.

Table 3. TPC, TFC, and antioxidant activities of olive leaf extracts from 32 cultivars.

\begin{tabular}{|c|c|c|c|c|c|c|}
\hline Code & Oil Content & $\begin{array}{c}\text { TPC } \\
(\mathrm{mg} \mathrm{GAE} / \mathrm{g} \mathrm{dw})\end{array}$ & $\begin{array}{c}\text { TFC } \\
\text { (mg RE/g dw) }\end{array}$ & $\begin{array}{c}\text { DPPH } \\
(\mathrm{mg} \mathrm{TE} / \mathrm{g} \mathrm{dw})\end{array}$ & $\begin{array}{c}\text { FRAP } \\
(\mathrm{mg} \mathrm{TE} / \mathrm{g} \mathrm{dw})\end{array}$ & $\begin{array}{c}\text { ABTS } \\
(\mathrm{mg} \mathrm{TE} / \mathrm{g} \mathrm{dw})\end{array}$ \\
\hline OL1 & $\mathrm{H}$ & $16.23 \pm 0.23^{\mathrm{b}-\mathrm{h}}$ & $72.79 \pm 24.00^{a b}$ & $176.99 \pm 8.43$ & $385.13 \pm 50.20^{a}$ & $279.71 \pm 17.57^{a}$ \\
\hline OL2 & $\mathrm{L}$ & $16.42 \pm 0.15^{\mathrm{c}-\mathrm{i}}$ & $94.61 \pm 10.87^{\mathrm{a}-\mathrm{c}}$ & $179.27 \pm 4.47$ & $765.99 \pm 25.98^{\mathrm{e}-\mathrm{i}}$ & $541.13 \pm 10.79^{b-g}$ \\
\hline OL3 & $\mathrm{L}$ & $16.87 \pm 0.41^{\mathrm{g}-\mathrm{j}}$ & $174.22 \pm 16.01^{\mathrm{e}}$ & $178.62 \pm 3.40$ & $1099.99 \pm 14.30 \mathrm{kl}$ & $758.01 \pm 16.54^{1}$ \\
\hline OL4 & $\mathrm{L}$ & $16.95 \pm 0.40^{h-j}$ & $83.71 \pm 15.19^{a b}$ & $178.56 \pm 3.47$ & $674.92 \pm 62.07^{b-g}$ & $494.09 \pm 32.17^{b c}$ \\
\hline OL5 & M & $16.57 \pm 0.19^{\mathrm{d}-\mathrm{i}}$ & $127.97 \pm 20.21^{\mathrm{a}-\mathrm{e}}$ & $176.54 \pm 3.27$ & $1139.86 \pm 17.05^{\mathrm{kl}}$ & $637.53 \pm 8.43^{\mathrm{g}-\mathrm{k}}$ \\
\hline OL6 & $\mathrm{H}$ & $16.10 \pm 0.19^{\mathrm{b}-\mathrm{g}}$ & $77.19 \pm 20.20 \mathrm{ab}$ & $180.12 \pm 3.50$ & $666.07 \pm 12.74^{b-g}$ & $446.16 \pm 16.42^{b}$ \\
\hline OL7 & $\mathrm{L}$ & $16.36 \pm 0.17^{\mathrm{b}-\mathrm{i}}$ & $133.72 \pm 12.19^{b-e}$ & $176.25 \pm 2.20$ & $952.77 \pm 94.68^{i-k}$ & $612.91 \pm 18.27^{\mathrm{d}-\mathrm{k}}$ \\
\hline OL8 & M & $15.60 \pm 0.46^{\mathrm{ab}}$ & $109.86 \pm 9.37^{a-e}$ & $175.63 \pm 1.20$ & $836.55 \pm 20.28^{g-j}$ & $519.86 \pm 7.34^{\mathrm{b}-\mathrm{e}}$ \\
\hline OL9 & $\mathrm{L}$ & $15.91 \pm 0.16^{\mathrm{a}-\mathrm{f}}$ & $176.30 \pm 20.04^{\mathrm{e}}$ & $180.22 \pm 1.84$ & $1228.29 \pm 23.95^{1}$ & $623.75 \pm 10.08^{f-k}$ \\
\hline OL10 & M & $16.71 \pm 0.24^{\mathrm{f}-\mathrm{j}}$ & $132.60 \pm 2.52^{\mathrm{b}-\mathrm{e}}$ & $174.14 \pm 0.93$ & $900.53 \pm 83.56^{h-j}$ & $603.78 \pm 27.91^{\mathrm{d}-\mathrm{j}}$ \\
\hline OL11 & $\mathrm{L}$ & $16.41 \pm 0.25^{\mathrm{b}-\mathrm{i}}$ & $62.44 \pm 26.05^{a}$ & $175.27 \pm 0.90$ & $738.49 \pm 28.74^{\mathrm{d}-\mathrm{h}}$ & $526.05 \pm 33.80^{b-f}$ \\
\hline OL12 & $\mathrm{L}$ & $16.34 \pm 0.17^{\mathrm{b}-\mathrm{i}}$ & $111.50 \pm 22.45^{\mathrm{a}-\mathrm{e}}$ & $173.98 \pm 1.58$ & $989.40 \pm 21.17^{\mathrm{jk}}$ & $598.43 \pm 13.70^{\mathrm{d}-j}$ \\
\hline OL13 & M & $16.23 \pm 0.35^{\mathrm{b}-\mathrm{h}}$ & $156.56 \pm 0.76^{\mathrm{c}-\mathrm{e}}$ & $177.23 \pm 0.36$ & $984.01 \pm 17.04^{\mathrm{jk}}$ & $670.33 \pm 18.34^{\mathrm{i}-1}$ \\
\hline OL14 & $\mathrm{L}$ & $15.81 \pm 0.24^{\mathrm{a}-\mathrm{d}}$ & $116.71 \pm 19.47^{\mathrm{a}-\mathrm{e}}$ & $176.26 \pm 1.07$ & $729.84 \pm 16.91^{\mathrm{d}-\mathrm{h}}$ & $710.64 \pm 14.58^{\mathrm{kl}}$ \\
\hline OL15 & $\mathrm{H}$ & $16.69 \pm 0.17^{f-j}$ & $71.89 \pm 16.82^{a b}$ & $176.76 \pm 0.95$ & $666.17 \pm 8.56^{\mathrm{b}-\mathrm{g}}$ & $609.78 \pm 5.55^{\mathrm{d}-\mathrm{k}}$ \\
\hline OL16 & M & $16.09 \pm 0.37^{\mathrm{b}-\mathrm{g}}$ & $98.13 \pm 17.84^{\mathrm{a}-\mathrm{c}}$ & $174.91 \pm 2.58$ & $809.46 \pm 27.34^{\mathrm{f}-\mathrm{j}}$ & $643.48 \pm 19.09 \mathrm{~g}-\mathrm{k}$ \\
\hline OL17 & $\mathrm{L}$ & $16.63 \pm 0.27^{\mathrm{e}-\mathrm{i}}$ & $117.15 \pm 25.21^{\mathrm{a}-\mathrm{e}}$ & $176.32 \pm 0.72$ & $755.47 \pm 47.44^{\mathrm{e}-\mathrm{h}}$ & $603.15 \pm 23.80^{d-j}$ \\
\hline OL18 & $\mathrm{H}$ & $16.85 \pm 0.19^{g-j}$ & $100.20 \pm 15.16^{a-c}$ & $177.01 \pm 0.64$ & $667.83 \pm 20.57^{b-g}$ & $543.22 \pm 9.74^{b-g}$ \\
\hline OL19 & $\mathrm{L}$ & $15.60 \pm 0.05^{a b}$ & $109.34 \pm 7.73^{\mathrm{a}-\mathrm{d}}$ & $171.10 \pm 6.95$ & $902.11 \pm 46.12^{\mathrm{h}-\mathrm{j}}$ & $684.90 \pm 3.00^{j-1}$ \\
\hline OL20 & M & $16.93 \pm 0.29^{h-j}$ & $116.32 \pm 9.32^{\mathrm{a}-\mathrm{e}}$ & $173.21 \pm 1.50$ & $709.83 \pm 12.35^{c-g}$ & $624.14 \pm 20.01^{\mathrm{f}-\mathrm{k}}$ \\
\hline OL21 & M & $16.26 \pm 0.25^{\mathrm{b}-\mathrm{i}}$ & $97.38 \pm 12.82^{a-c}$ & $175.51 \pm 0.72$ & $675.07 \pm 28.56^{\mathrm{b}-\mathrm{g}}$ & $627.88 \pm 16.66^{f-k}$ \\
\hline OL22 & $\mathrm{H}$ & $15.70 \pm 0.18^{a-c}$ & $103.38 \pm 1.98^{a-c}$ & $173.26 \pm 2.44$ & $710.58 \pm 11.15^{\mathrm{c}-\mathrm{g}}$ & $584.71 \pm 14.90^{\mathrm{c}-\mathrm{j}}$ \\
\hline OL23 & $\mathrm{H}$ & $15.13 \pm 0.19^{a}$ & $125.42 \pm 12.40^{\mathrm{a}-\mathrm{e}}$ & $175.32 \pm 2.65$ & $743.95 \pm 13.34^{\mathrm{d}-\mathrm{h}}$ & $622.64 \pm 13.13^{\mathrm{e}-\mathrm{k}}$ \\
\hline OL24 & M & $15.77 \pm 0.19^{a-d}$ & $132.18 \pm 18.98^{b-e}$ & $175.90 \pm 2.87$ & $637.54 \pm 16.82^{b-f}$ & $594.99 \pm 11.18^{c-j}$ \\
\hline OL25 & M & $16.70 \pm 0.09^{f-j}$ & $77.72 \pm 18.84^{\mathrm{ab}}$ & $174.31 \pm 0.70$ & $516.82 \pm 14.34^{\mathrm{ab}}$ & $575.63 \pm 18.34^{\mathrm{c}-\mathrm{i}}$ \\
\hline OL26 & $\mathrm{H}$ & $16.26 \pm 0.16^{\mathrm{b}-\mathrm{i}}$ & $93.57 \pm 10.43^{\mathrm{a}-\mathrm{c}}$ & $176.70 \pm 0.81$ & $516.90 \pm 16.22 \mathrm{ab}$ & $511.46 \pm 13.69^{b-d}$ \\
\hline OL27 & M & $15.77 \pm 0.27^{\mathrm{a}-\mathrm{d}}$ & $117.31 \pm 19.59^{\mathrm{a}-\mathrm{e}}$ & $176.21 \pm 0.41$ & $620.80 \pm 14.89^{b-e}$ & $631.50 \pm 15.25^{\mathrm{g}-\mathrm{k}}$ \\
\hline OL28 & $\mathrm{L}$ & $16.11 \pm 0.19^{\mathrm{b}-\mathrm{g}}$ & $108.21 \pm 19.78^{\mathrm{a}-\mathrm{d}}$ & $176.74 \pm 1.24$ & $671.57 \pm 36.85^{\mathrm{b}-\mathrm{g}}$ & $658.19 \pm 19.80^{\mathrm{h}-1}$ \\
\hline OL29 & $\mathrm{H}$ & $15.71 \pm 0.38^{a-c}$ & $114.58 \pm 8.76^{\mathrm{a}-\mathrm{e}}$ & $177.11 \pm 0.46$ & $505.07 \pm 20.15^{a b}$ & $557.46 \pm 23.16^{c-h}$ \\
\hline OL30 & $\mathrm{H}$ & $15.85 \pm 0.08^{\mathrm{a}-\mathrm{e}}$ & $108.89 \pm 3.29^{a-d}$ & $174.51 \pm 0.66$ & $557.54 \pm 2.84^{\mathrm{a}-\mathrm{d}}$ & $563.59 \pm 14.64^{\mathrm{c}-\mathrm{h}}$ \\
\hline OL31 & M & $17.49 \pm 0.12^{\mathrm{j}}$ & $102.23 \pm 7.94^{\mathrm{a}-\mathrm{c}}$ & $177.22 \pm 1.22$ & $526.39 \pm 17.86^{a-c}$ & $550.35 \pm 7.54^{c-g}$ \\
\hline OL32 & M & $17.04 \pm 0.24 \mathrm{ij}$ & $115.23 \pm 21.14^{\mathrm{a}-\mathrm{e}}$ & $176.06 \pm 0.58$ & $599.90 \pm 9.56^{\mathrm{b}-\mathrm{e}}$ & $624.58 \pm 23.24^{\mathrm{f}-\mathrm{k}}$ \\
\hline
\end{tabular}

Note: Results are expressed as mean $\pm \mathrm{SD}(\mathrm{n}=3){ }^{\mathrm{a}-\mathrm{l}}$ Means in the same column with unlike superscripts differ significantly $(p<0.05)$. H, M, and L represent high-oil-content (>20\%) olive cultivars, medium-oil-content $(16-20 \%)$ olive cultivars, and low-oil-content $(<16 \%)$ olive cultivars, respectively.

The TFCs significantly differed between the cultivars. Among the studied cultivars, OL9 exhibited the highest TFC value in the leaf extracts $(176.30 \pm 20.04 \mathrm{mg} \mathrm{RE} / \mathrm{g} \mathrm{dw})$, followed by OL3 (174.22 $\pm 16.01 \mathrm{mg}$ RE/g dw), whereas OL15 (Nikitskii I) and OL1 
exhibited the lowest amount of TFCs $(71.89 \pm 16.82$ and $72.79 \pm 24.00 \mathrm{mg}$ RE/g dw, respectively). The TFCs obtained in this study were substantially greater than those reported by Gullon et al. (11.52 to $52.82 \mathrm{mg} \mathrm{RE/gdw)} \mathrm{[41]} \mathrm{and} \mathrm{comparable} \mathrm{to} \mathrm{those} \mathrm{obtained}$ for cultivar Picual leaf extracts (approximately $66.7 \mathrm{mg} \mathrm{RE} / \mathrm{g} \mathrm{dw}$ ) [12]. Multiple factors, including extraction treatment, harvesting season, climate, variety, and ripening degree, can affect the composition and concentrations of bioactive chemicals [19] in leaf extracts. Thus, it is difficult to compare the data obtained in this study with data in the literature.

The antioxidant activities of the olive leaf extracts from the 32 cultivars were evaluated by three complementary methods: DPPH, ABTS, and FRAP assays, which were based on radical scavenging ability and reducing power. As shown in Table 3, no significant differences $(p>0.05)$ in DPPH-based antioxidant activity were determined between the cultivars. Antioxidant activities varied between $171.10 \pm 6.95$ and $180.12 \pm 3.50 \mathrm{mg}$ TE/g dw However, the olive leaves of the investigated varieties showed statistically significant ABTS- and FRAP-based antioxidant activities, and their overall trends were similar to those for the total quantities of individual phenolics and TFC. Similarly, OL3 and OL14 were in the low-oil-content category and exhibited the highest ABTS values (758.01 \pm 16.54 and $710.64 \pm 14.58 \mathrm{mg} \mathrm{TE} / \mathrm{g} \mathrm{dw}$, respectively), while the high-oil-content cultivar, OL1, exhibited the lowest ABTS value (279.71 $\pm 17.57 \mathrm{mg}$ TE/g dw). For the FRAP values, OL9 (L), OL5 (M), and OL3 (L) exhibited the highest values, at 1228.29 $\pm 23.95,1139.86 \pm 17.05$, and $1099.99 \pm 14.30 \mathrm{mg}$ TE/g dw, respectively, which coincided with the maximum TFC value. OL1 also had the lowest FRAP value of $385.13 \pm 50.20 \mathrm{mg}$ TE/g dw. As expected, the high-oil-content cultivars had the lowest antioxidant values (Figure S2D,E). In addition, the variations between the results of the DPPH, ABTS, and FRAP assays were attributed to the use of different radicals in the different methods, as the various compounds reacted differently with the employed radicals [42]. Consequently, our findings showed that combining antioxidant capacity assays was more accurate than using only the DPPH assay.

\subsection{Multivariate Data Analysis \\ 3.3.1. Correlation Analysis}

The correlations between antioxidant activity (DPPH, ABTS, and FRAP assays) and TPC, TFC, and the concentrations of the individual phytochemicals of olive leaves were determined using Pearson's and Spearman's rank correlation analyses. No significant correlations were found between TPC and antioxidant activity (DPPH, ABTS, and FRAP assays; Figure S3); however, the total quantities of phenolic compounds were highly correlated with the ABTS-based $(\mathrm{r}=0.6389 ; p<0.001)$ and FRAP-based antioxidant activities $(\mathrm{r}=0.7808 ; p<0.001$; Figure 3$)$. This discrepancy was attributed to the non-specificity of the colorimetric method for TPC [43]. Furthermore, the TFCs also showed significant $(p<0.001$; Figure S3) positive correlations with the ABTS-based $(r=0.6856)$ and FRAPbased antioxidant activities $(\mathrm{r}=0.6236)$. Flavonoids, the major groups of polyphenols in olive leaves, have shown to be major contributors to the demonstrated antioxidant activity of olive leaf extracts, due to their free hydroxyl groups and catechol structures [44]. The correlation between antioxidant activity and the concentrations of individual phenolics confirmed that the synergistic effect of a larger number of flavonoids led to the antioxidant behavior of the olive leaves. Kaempferol-7-O-glucoside, luteolin-7-O-glucoside, luteolin-3',7-di-O-glucoside, luteolin-4' -O-glucoside, and rutin showed strong significant correlations $(r=0.5244-0.7627 ; p<0.001)$ with the ABTS and FRAP values. In addition to the flavonoids, oleuropein, secoxyloganin, esculin, and hydroxytyrosol concentrations also showed significant $(p<0.01)$ positive correlations with antioxidant activities for the ABTS and FRAP values. Despite the high concentrations of oleuropein identified in the olive leaf extracts, oleuropein showed weaker correlations with antioxidant activity than hydroxytyrosol. A previous study reported that the antioxidant activity of oleuropein was mainly due to the aglycones (i.e., hydroxytyrosol moietyin) in its structure [13]. The antioxidant activity of plant-derived samples has shown to be a complicated action that could be synergistically promoted by the various phenolic compounds in the plant [42] 
Similarly, the antioxidant behavior of olive leaf extracts may largely depend on the interactions of bioactive chemicals, including flavonoids, secoiridoids, and hydroxytyrosol $[13,44]$. Nevertheless, modern analytical techniques such as DPPH•/ABTS•+/FRAP, coupled with ultra-high-performance liquid chromatography-high-resolution mass spectrometry, should be further used to identify and screen the main antioxidant compounds in olive leaves [45].

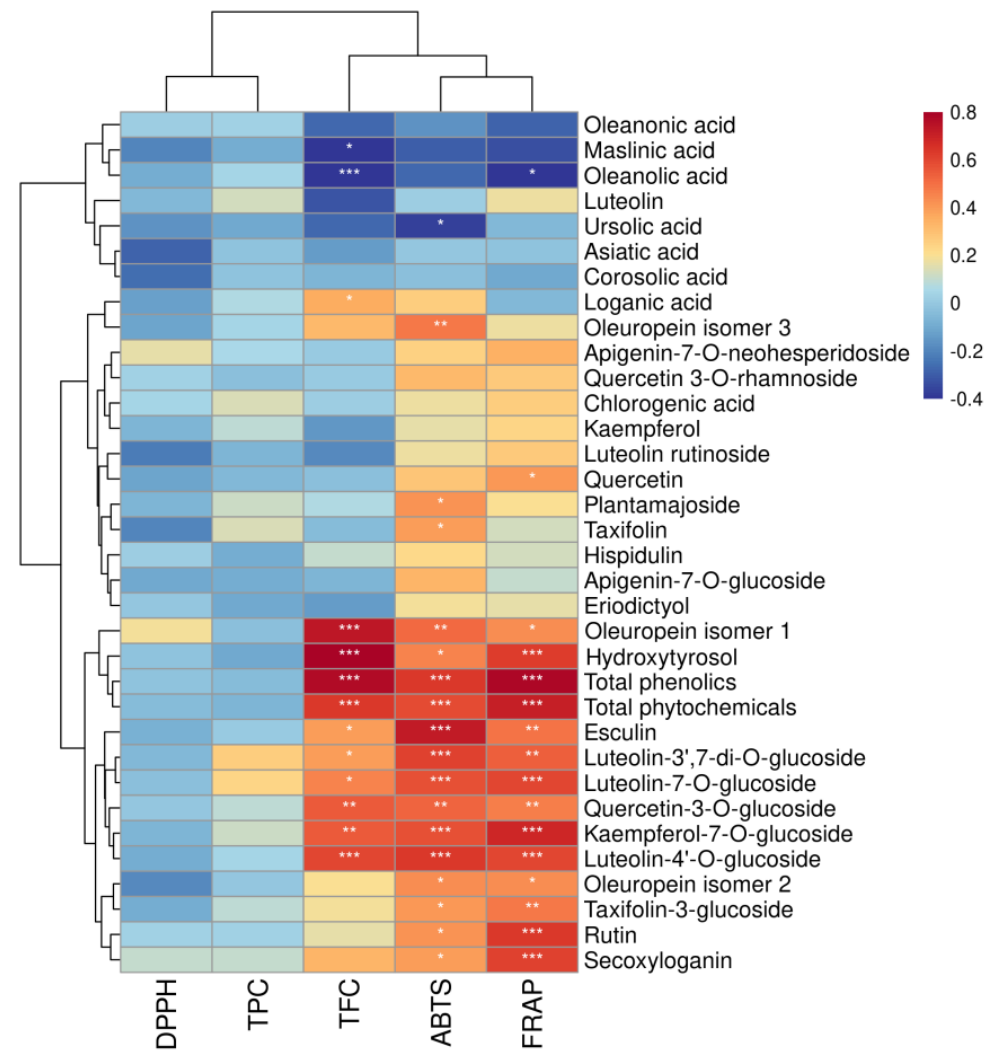

Figure 3. Heatmap of Spearman's rank correlations between the individual phytochemicals and five variables (TPC, TFC, DPPH, ABTS, and FRAP) of the olive leaf extracts. Significance levels are indicated as follows: ${ }^{*}: p<0.05 ;{ }^{* *}: p<0.01 ;{ }^{* * *}: p<0.001$.

\subsubsection{PCA}

Principal component analysis (PCA) has been widely used as an exploratory analysis to decrease the dimensionality of large datasets and to reflect similarities or differences among plant samples $[24,43]$. In the present study, the analysis was conducted using a complete dataset obtained from 32 cultivars (i.e., TPC, TFC, the concentrations of 32 phytochemical compounds, and the antioxidant activities of DPPH, ABTS, and FRAP). The first four principal components (PCs) with eigenvalues $>2$ explained $64.8 \%$ of total variance (PC1 35.2\%, PC2 13.7\%, PC2 8.4\%, and PC4 7.5\%). As shown in Figure S4, the eigenvalue dropped significantly after the first two PCs. Thus, PC1 and PC2 were used to visualize the correlation between variables. The distribution of the 32 olive cultivars on a plane is shown in Figure 4A, and the contribution of each parameter is shown in the PCA loading plot (Figure 4B). As shown in the score plots, cultivars with medium oil content could not be differentiated as groups, due to their high variability, and were randomly distributed in Figure 4A. However, the first principal component separated the high-oil-content and low-oil-content cultivars. The variables that contributed most to PC1 (positive) were glycosylated flavonoids (e.g., rutin, luteolin-7-O-glucoside, luteolin4'-O-glucoside, kaempferol-7-O-glucoside, and luteolin-3', ,7-di-O-glucoside), oleuropein isomer 1, secoxyloganin, hydroxytyrosol, and antioxidant capacity parameters (ABTS and FRAP). In addition, triterpenic acids (i.e., oleanonic, maslinic, and oleanolic acids) had a strong negative influence on PC1. The leaves of the high-oil-content olive cultivars were 
positioned on the left side of the diagram and exhibited the lowest polyphenol concentrations and related antioxidant activities; however, they also had the highest triterpenic acid concentrations. Most of the low-oil-content cultivar leaves were concentrated on the right side (except for OL4) and exhibited the highest concentrations of glycosylated flavonoids, oleuropein, and hydroxytyrosol. These results were similar to the ANOVA results (Figure 2), which showed that the flavonoids, iridoids, and triterpenic acids were substantially different among the three categories in terms of oil content. In addition, analysis of the interdependencies between antioxidant activity (ABTS and FRAP) and individual polyphenols revealed that rutin, luteolin-7-O-glucoside, luteolin-4'-O-glucoside, kaempferol-7-O-glucoside, oleuropein, and hydroxytyrosol synergistically contributed to antioxidant activity, which was consistent with the correlation analysis results. In summary, the olive leaves from the varieties rich in these compounds could potentially provide high antioxidant activity and nutraceutical benefits.



Figure 4. PCA results based on the mean values of 32 phytochemicals and five variables (TPC, TFC, DPPH, ABTS, and FRAP): (A) score plot and (B) loading plot. H, M, and L represent high-oil-content (>20\%) olive cultivars, medium-oil-content (16-20\%) olive cultivars, and low-oil-content $(<16 \%)$ olive cultivars, respectively. 


\section{Conclusions}

This study evaluated the phytochemical profiles and antioxidant potential of olive leaves from 32 cultivars grown in China and revealed that olive leaves were excellent sources of flavonoids, iridoids, and triterpenic acids. TPC, TFC, and the individual phytochemical concentrations in the olive leaves varied considerably among the different cultivars, resulting in the various antioxidant activities of the different cultivars. Additionally, for the first time, we assessed olive cultivars for both oil contents and useful by-products from the leaves, simultaneously. Among the investigated cultivars, we found that leaves from the low-oil-content cultivars were characterized by high concentrations of glycosylated flavonoids, oleuropein, and hydroxytyrosol, whereas the high-oil-content olive cultivars were rich in triterpenic acids (i.e., oleanonic, maslinic, and oleanolic acid). Accordingly, it was suggested that olive leaves obtained from low-oil-content cultivars may be good candidates for flavonoid and oleuropein separation, whereas cultivars with high oil content may be suitable for the extraction of triterpenic acids. In future studies, it would be interesting to clarify the reason for the correlation between oil content and phytochemical compounds in leaves among different cultivars.

Supplementary Materials: Figure S1: Leaves from the 32 investigated olive cultivars; Figure S2: TPC, TFC, and antioxidant activities of olive leaf extracts from 32 cultivars; Figure S3: Pearson's correlation scatter plot of the relationships between (A) DPPH and TPC, (B) FRAP and TPC, (C) ABTS and TPC, (D) DPPH and TFC, (E) FRAP and TFC, and (F) ABTS and TFC; Figure S4: Eigenvalues for principal component analysis (PCA); Table S1: Quantitative amounts of flavonols (mg/g dw) in olive leaf extractsfrom 32 different cultivars; Table S2: Quantitative amounts of simple phenols, coumarins, iridoids, triterpenic acids, and hydroxycinnamic acid $(\mathrm{mg} / \mathrm{g} \mathrm{dw})$ in olive leaf extracts from 32 different cultivars.

Author Contributions: Conceptualization, C.Z. and D.L.; methodology, X.X. and Z.Z.; software, J.Z.; investigation, C.Z.; resources, S.Z. and E.N.; data curation, C.Z., X.X. and J.Z.; writing-original draft preparation, C.Z. and X.X.; writing-review and editing, D.L.; supervision, D.L; funding acquisition, C.Z. and S.Z. All authors have read and agreed to the published version of the manuscript.

Funding: This work was financially supported by the Key Research and Development Project of Zhejiang Province (2021C02002).

Institutional Review Board Statement: Not applicable.

Informed Consent Statement: Not applicable.

Data Availability Statement: All the data generated by this research are included in the article.

Conflicts of Interest: The authors declare no conflict of interest.

\section{References}

1. Talhaoui, N.; Taamalli, A.; Maria Gomez-Caravaca, A.; Fernandez-Gutierrez, A.; Segura-Carretero, A. Phenolic compounds in olive leaves: Analytical determination, biotic and abiotic influence, and health benefits. Food Res. Int. 2015, 77, 92-108. [CrossRef]

2. Yang, L.; Ma, J.; Hou, C.; Lu, X.; Yan, H.; Kong, W.; Deng, Y. Evolution of phenotypic traits and main functional components in the fruit of 'Chenggu-32' olives (Olea europaea L.) cultivated in longnan (China). J. Oleo Sci. 2020, 69, 973-984. [CrossRef] [PubMed]

3. Zugcic, T.; Abdelkebir, R.; Alcantara, C.; Carmen Collado, M.; Vicente Garcia-Perez, J.; Melendez-Martinez, A.J.; Jambrak, A.R.; Lorenzo, J.M.; Barba, F.J. From extraction of valuable compounds to health promoting benefits of olive leaves through bioaccessibility, bioavailability and impact on gut microbiota. Trends Food Sci. Technol. 2019, 83, 63-77. [CrossRef]

4. Paskovic, I.; Lukic, I.; Zurga, P.; Majetic, G.V.; Brkljaca, M.; Koprivnjak, O.; Major, N.; Grozic, K.; Franic, M.; Ban, D.; et al. Temporal variation of phenolic and mineral composition in olive leaves is cultivar dependent. Plants 2020, 9, 1099. [CrossRef] [PubMed]

5. Lama-Munoz, A.; Contreras, M.; Espinola, F.; Moya, M.; Romero, I.; Castro, E. Content of phenolic compounds and mannitol in olive leaves extracts from six Spanish cultivars: Extraction with the Soxhlet method and pressurized liquids. Food Chem. 2020, 320, 126626. [CrossRef] [PubMed]

6. Alcantara, C.; Zugcic, T.; Abdelkebir, R.; Garcia-Perez, J.V.; Jambrak, A.R.; Lorenzo, J.M.; Collado, M.C.; Granato, D.; Barba, F.J. Effects of Ultrasound-Assisted extraction and solvent on the phenolic profile, bacterial growth, and Anti-Inflammatory/Antioxidant activities of mediterranean olive and fig leaves extracts. Molecules 2020, 25, 1718. [CrossRef] 
7. Rodrigues, F.; Pimentel, F.B.; Oliveira, M.B.P.P. Olive by-products: Challenge application in cosmetic industry. Ind. Crop. Prod. 2015, 70, 116-124. [CrossRef]

8. Azar, F.A.N.; Pezeshki, A.; Ghanbarzadeh, B.; Hamishehkar, H.; Mohammadi, M.; Hamdipour, S.; Daliri, H. Pectin-sodium caseinat hydrogel containing olive leaf extract-nano lipid carrier: Preparation, characterization and rheological properties. LWT Food Sci. Technol. 2021, 148, 111757. [CrossRef]

9. Faccioli, L.S.; Klein, M.P.; Borges, G.R.; Dalanhol, C.S.; Machado, I.C.K.; Garavaglia, J.; Dal Bosco, S.M. Development of crackers with the addition of olive leaf flour (Olea europaea L.): Chemical and sensory characterization. LWT Food Sci. Technol. 2021, 141, 110848. [CrossRef]

10. Lafka, T.; Lazou, A.E.; Sinanoglou, V.J.; Lazos, E.S. Phenolic extracts from wild olive leaves and their potential as edible oils antioxidants. Foods 2013, 2, 18-31. [CrossRef]

11. Moghaddam, M.F.T.; Jalali, H.; Nafchi, A.M.; Nouri, L. Evaluating the effects of lactic acid bacteria and olive leaf extract on the quality of gluten-free bread. Gene Rep. 2020, 21, 100771. [CrossRef]

12. Lama-Munoz, A.; Del, M.C.M.; Espinola, F.; Moya, M.; de Torres, A.; Romero, I.; Castro, E. Extraction of oleuropein and luteolin-7-O-glucoside from olive leaves: Optimization of technique and operating conditions. Food Chem. 2019, 293, 161-168. [CrossRef] [PubMed]

13. Contreras, M.; Lama-Munoz, A.; Espinola, F.; Moya, M.; Romero, I.; Castro, E. Valorization of olive mill leaves through ultrasound-assisted extraction. Food Chem. 2020, 314, 126218. [CrossRef] [PubMed]

14. Jurišić Grubešić, R.; Nazlić, M.; Miletić, T.; Vuko, E.; Vuletić, N.; Ljubenkov, I.; Dunkić, V. Antioxidant capacity of free volatile compounds from olea europaea 1. cv. oblica leaves depending on the vegetation stage. Antioxidants 2021, 10, 1832. [CrossRef] [PubMed]

15. Nicoli, F.; Negro, C.; Vergine, M.; Aprile, A.; Nutricati, E.; Sabella, E.; Miceli, A.; Luvisi, A.; De Bellis, L. Evaluation of phytochemical and antioxidant properties of 15 Italian Olea europaea L. cultivar leaves. Molecules 2019, 24, 1998. [CrossRef]

16. Romero, C.; García, A.; Medina, E.; Ruíz-Méndez, M.V.; Castro, A.D.; Brenes, M. Triterpenic acids in table olives. Food Chem. 2010, 118, 670-674. [CrossRef]

17. Lorini, A.; Aranha, B.C.; Antunes, B.D.F.; Otero, D.M.; Jacques, A.C.; Zambiazi, R.C. Metabolic profile of olive leaves of different cultivars and collection times. Food Chem. 2021, 345, 128758. [CrossRef]

18. Kamran, M.; Hamlin, A.S.; Scott, C.J.; Obied, H.K. Drying at high temperature for a short time maximizes the recovery of olive leaf biophenols. Ind. Crop. Prod. 2015, 78, 29-38. [CrossRef]

19. Ahmad-Qasem, M.H.; Canovas, J.; Barrajon-Catalan, E.; Carreres, J.E.; Micol, V.; Garcia-Perez, J.V. Influence of olive leaf processing on the bioaccessibility of bioactive polyphenols. J. Agric. Food Chem 2014, 62, 6190-6198. [CrossRef]

20. Orak, H.H.; Karamac, M.; Amarowicz, R.; Orak, A.; Penkacik, K. Genotype-Related differences in the phenolic compound profile and antioxidant activity of extracts from olive (Olea europaea L.) leaves. Molecules 2019, 24, 1130. [CrossRef]

21. Deng, Y. The status quo and trends of China olive industry innovation-driven development and relevant countermeasures. Nonwood For. Res. 2018, 36, 1-6.

22. Beltran, G.; Uceda, M.; Jimenez, A.; Aguilera, M.P. Olive oil extractability index as a parameter for olive cultivar characterisation. J. Sci. Food Agric. 2003, 83, 503-506. [CrossRef]

23. Wang, J.; Ma, L.; Gomez-Del-Campo, M.; Zhang, D.; Deng, Y.; Jia, Z. Youth tree behavior of olive (Olea europaea L.) cultivars in Wudu, China: Cold and drought resistance, growth, fruit production, and oil quality. Sci. Hortic. 2018, 236, 106-122. [CrossRef]

24. Chang, C.C.; Yang, M.H.; Wen, H.M.; Chern, J.C. Estimation of total flavonoid content in propolis by two complementary colorimetric methods. J. Food Drug Anal. 2002, 10, 178-182.

25. Singleton, V.L.; Orthofer, R.; Lamuela-Raventos, R.M. Analysis of total phenols and other oxidation substrates and antioxidants by means of Folin-Ciocalteu reagent. In Methods in Enzymology; Elsevier: Amsterdam, The Netherlands, 1999; Volume 299, pp. 152-178.

26. Martinović, A.; Cavoski, I. The exploitation of cornelian cherry (Cornus mas L.) cultivars and genotypes from Montenegro as a source of natural bioactive compounds. Food Chem. 2020, 318, 126549. [CrossRef] [PubMed]

27. Leopoldini, M.; Marino, T.; Russo, N.; Toscano, M. Antioxidant properties of phenolic compounds: H-Atom versus electron transfer mechanism. J. Phys. Chem. A 2004, 108, 4916-4922. [CrossRef]

28. Oliveira, A.L.S.; Gondim, S.; Gómez-García, R.; Ribeiro, T.; Pintado, M. Olive leaf phenolic extract from two Portuguese cultivars-bioactivities for potential food and cosmetic application. J. Environ. Chem. Eng. 2021, 9, 106175. [CrossRef]

29. Alañón, M.E.; Ivanović, M.; Gómez-Caravaca, A.M.; Arráez-Román, D.; Segura-Carretero, A. Choline chloride derivative-based deep eutectic liquids as novel green alternative solvents for extraction of phenolic compounds from olive leaf. Arab. J. Chem. 2020, 13, 1685-1701. [CrossRef]

30. Abaza, L.; Taamalli, A.; Arraez-Roman, D.; Segura-Carretero, A.; Fernandez-Gutierrerez, A.; Zarrouk, M.; Youssef, N.B. Changes in phenolic composition in olive tree parts according to development stage. Food Res. Int. 2017, 100, 454-461. [CrossRef]

31. Vinha, A.F.; Ferreres, F.; Silva, B.M.; Valentão, P.; Gonçalves, A.; Pereira, J.A.; Oliveira, M.B.; Seabra, R.M.; Andrade, P.B. Phenolic profiles of Portuguese olive fruits (Olea europaea L.): Influences of cultivar and geographical origin. Food Chem. 2005, 89, 561-568. [CrossRef] 
32. Blasi, F.; Rocchetti, G.; Montesano, D.; Lucini, L.; Chiodelli, G.; Ghisoni, S.; Baccolo, G.; Simonetti, M.S.; Cossignani, L. Changes in extra-virgin olive oil added with Lycium barbarum L. carotenoids during frying: Chemical analyses and metabolomic approach. Food Res. Int. 2018, 105, 507-516. [CrossRef] [PubMed]

33. Aron, P.M.; Kennedy, J.A. Flavan-3-ols: Nature, occurrence and biological activity. Mol. Nutr. Food Res. 2008, 52, 79-104. [CrossRef]

34. Anastasiu, A.; Chira, N.; Banu, I.; Ionescu, N.; Stan, R.; Rosca, S. Oil productivity of seven Romanian linseed varieties as affected by weather conditions. Ind. Crop. Prod. 2016, 86, 219-230. [CrossRef]

35. Cecchi, L.; Migliorini, M.; Cherubini, C.; Giusti, M.; Zanoni, B.; Innocenti, M.; Mulinacci, N. Phenolic profiles, oil amount and sugar content during olive ripening of three typical Tuscan cultivars to detect the best harvesting time for oil production. Food Res. Int. 2013, 54, 1876-1884. [CrossRef]

36. Xie, P.; Huang, L.; Zhang, C.; Deng, Y.; Wang, X.; Cheng, J. Enhanced extraction of hydroxytyrosol, maslinic acid and oleanolic acid from olive pomace: Process parameters, kinetics and thermodynamics, and greenness assessment. Food Chem. 2019, 276, 662-674. [CrossRef] [PubMed]

37. Juan, M.E.; Planas, J.M. Cancer chemopreventive activity of maslinic acid, a pentacyclic triterpene from olives and olive oil. Olives Olive Oil Health Dis. Prev. 2021, 525-535. [CrossRef]

38. Lozano-Mena, G.; Sanchez-Gonzalez, M.; Juan, M.E.; Planas, J.M. Maslinic acid, a natural phytoalexin-type triterpene from olives-A promising nutraceutical? Molecules 2014, 19, 11538-11559. [CrossRef]

39. Guinda, Á.; Castellano, J.M.; Santos-Lozano, J.M.; Delgado-Hervás, T.; Gutiérrez-Adánez, P.; Rada, M. Determination of major bioactive compounds from olive leaf. LWT Food Sci. Technol. 2015, 64, 431-438. [CrossRef]

40. Gullon, B.; Gullon, P.; Eibes, G.; Cara, C.; De Torres, A.; Lopez-Linares, J.C.; Ruiz, E.; Castro, E. Valorisation of olive agro-industrial by-products as a source of bioactive compounds. Sci. Total Environ. 2018, 645, 533-542. [CrossRef]

41. Gullon, P.; Gullon, B.; Davila, I.; Labidi, J.; Gonzalez-Garcia, S. Comparative environmental life cycle assessment of integral revalorization of vine shoots from a biorefinery perspective. Sci. Total Environ. 2018, 624, 225-240. [CrossRef]

42. Bashmil, Y.M.; Ali, A.; Bk, A.; Dunshea, F.R.; Suleria, H.A.R. Screening and characterization of phenolic compounds from australian grown bananas and their antioxidant capacity. Antioxidants 2021, 10, 1521. [CrossRef] [PubMed]

43. Wu, H.; Chai, Z.; Hutabarat, R.P.; Zeng, Q.; Niu, L.; Li, D.; Yu, H.; Huang, W. Blueberry leaves from 73 different cultivars in southeastern China as nutraceutical supplements rich in antioxidants. Food Res. Int. 2019, 122, 548-560. [CrossRef] [PubMed]

44. Benavente-Garcia, O.; Castillo, J.; Lorente, J. Antioxidant activity of phenolics extracted from Olea europaea L. Leaves. Food Chem. 2000, 68, 457-462. [CrossRef]

45. Ma, Q.; Cai, S.; Liu, X.; Shi, J.; Yi, J. Characterization of phytochemical components and identification of main antioxidants in Crateva unilocalaris Buch. Shoots by UHPLC-Q-Orbitrap-MS(2) analysis. Food Res. Int. 2021, 143, 110264. [CrossRef] 